\title{
O NEOLIBERALISMO COMO OFENSIVA NEOCONSERVADORA À EDUCAÇÃO BRASILEIRA
}

\author{
Marília Gouvea de Miranda \\ Universidade Federal de Goiás (UFG), Goiânia, Goiás, Brasil
}

\begin{abstract}
Resumo: O objetivo deste artigo é introduzir um debate sobre o neoliberalismo em seus aspectos conceituais e históricos, tendo em vista os desafios postos por esse processo em sua nova etapa no Brasil e algumas de suas particularidades. Para tanto, o ponto de partida é uma discussão sobre o liberalismo, com a finalidade de situar as bases que serão preservadas ou recriadas sob o neoliberalismo contemporâneo, sempre com a preocupação de situar, histórica e conceitualmente, os processos que são próprios do modo de produção capitalista. Em seguida, pretende-se apreender os aspectos constitutivos desse neoliberalismo contemporâneo e situá-los na perspectiva de seus desdobramentos e de algumas questões relativas à educação como uma política social, uma dimensão da cultura ou uma prática escolar.
\end{abstract}

Palavras-chave: Neoliberalismo. Neoliberalismo e educação. Neoconservadorismo.

A fase atual do desenvolvimento do capitalismo, caracterizada especialmente pelo neoliberalismo e pela financeirização do capital', vem produzindo resultados extremos relativos ao aumento da concentração de riqueza, ao aprofundamento brutal das desigualdades sociais e ao incremento de novas e ainda mais deletérias formas de exploração da força de trabalho. Nesse compasso, está em curso também a escalada do conservadorismo, intensificado pelos movimentos de extrema-direita, que cerram trincheiras em defesa dos interesses do capital, não importa o quanto sejam destrutivos os seus resultados.

No Brasil, desde o golpe de Estado de 2016, o neoliberalismo aqui aportado vem ganhando renovado fôlego. Tirou da obscuridade um aprendiz de Chicago Boy desacreditado entre os próprios neoliberais, requentou os mantras do neoliberalismo chileno e vem agindo destemidamente para restaurar um programa que investe contra os direitos dos trabalhadores e revela um absoluto desprezo para com as classes populares, situando-as à margem dos interesses de uma elite cada vez mais disposta a se vincular a segmentos fortemente obscurantistas, autoritários e fascistas da sociedade.

O percurso do processo de neoliberalização no Brasil, que foi efetivamente iniciado nos governos de Fernando Henrique Cardoso (Partido da Social Democracia Brasileiro - PSDB), no período de 1995 a 2002, encontrou alguma (mas não completa ou radical) resistência nos governos subsequentes (2003-2016) do Partido dos Trabalhadores (PT), cujo projeto desenvolvimentista foi sustentado pelo bloco de poder constituído por 
boa parte da burguesia interna e industrializada e suas alianças com outros setores, compreendendo "uma parte da baixa classe média, a maior parte da classe operária, do campesinato e dos trabalhadores da massa marginal" (BOITO JR., 2016, p. 27). O golpe de Estado de 2016 assegurou a ascensão de outro bloco de poder constituído pela parcela da burguesia integrada ao grande capital internacional, com o apoio da alta classe média, que se sentiu ameaçada com as medidas de distribuição de renda e de melhoria das condições das classes populares durante os governos do PT (BOITO JR., 2018). Em 2018, desde a campanha eleitoral de Jair Bolsonaro, esse bloco de poder neoliberal tem incorporado outros segmentos da sociedade, caracterizados por inserções muito diversificadas - desde proprietários de terra e extrativistas, militares, religiosos neopentecostais até conservadores terraplanistas e milicianos - que, em seu conjunto, também tem constituído a base de apoio para a ofensiva neoliberal na economia e em todos os demais setores da sociedade brasileira de um modo sem precedentes em nossa história.

É sabido que, em seu percurso, o neoliberalismo exige se espraiar por todas as formas da vida social, política e cultural de maneira mais ou menos evidente embora definitiva. Particularmente, seus interesses incidem sobre as políticas sociais com destaque para a educação. Nos anos de 1990, ainda no Brasil, já estava em curso a escalada do conservadorismo e da "nova" direita nesse campo - processo que se atualiza de maneira definitiva hoje. Parte substantiva da produção acadêmica ${ }^{2}$ desses anos, a par de tudo quanto a possa distinguir do ponto de vista teórico e metodológico, já indicava tendências que permitiriam apreender, já naquele momento, processos em desenvolvimento no campo das políticas públicas e da educação, que ressoariam e, pois, antecipariam a estratégia neoliberal de conquista hegemônica consolidada no cenário atual:

O que está em jogo não é apenas uma reestruturação neoliberal das esferas econômica, social e política, mas uma reelaboração e redefinição das próprias formas de representação social. O projeto neoconservador e neoliberal envolve, certamente, a criação de um espaço em que se torne impossível pensar o econômico, o político e o social fora das categorias que justificam o arranjo social capitalista. Nesse espaço hegemônico, visões alternativas e contrapostas à liberal/capitalista são reprimidas a ponto de desaparecerem da imaginação e do pensamento até mesmo daqueles grupos mais vitimados pelo presente sistema, cujos males, estranhamente, são atribuídos não ao seu núcleo econômico - capitalista - mas ao suposto fato de que ainda não é suficientemente capitalista ${ }^{3}$. (SILVA, 1994, p. 13-14).

Além disso, nessa mesma época, nos Estados Unidos, Michael Apple (2003) realizava estudos sobre o avanço da direita em relação à educação de seu país, abordando a aliança entre o neoliberalismo e o neoconservadorismo. Adotou uma tipologia mais abrangente que, ademais de considerar os grupos neoliberais mais identificados com o mercado e com as liberdades individuais, e os neoconservadores mais apegados a valores tradicionais e disciplinares, nomeava também os populistas autoritáriosfundamentalistas religiosos e evangélicos conservadores, e a nova classe média de gerentes e profissionais. 
MIRANDA, M. G. de

Partindo do pressuposto de que esses movimentos eram distintos, sua questão era compreender como se resolveria, na prática da educação, a contradição entre posições em princípio opostas como aquelas assumidas pelo neoliberalismo e pelo neoconservadorismo.

Diferentemente do que ocorreu nos Estados Unidos, onde os processos de neoliberalização dos anos 1990 não encontraram obstáculos mais significativos em seu curso, no Brasil e em outros países da América Latina, após os governos progressistas dos primeiros anos deste século ${ }^{4}$, a retomada e o aprofundamento das estratégias neoliberais repõem a necessidade de discutir o neoliberalismo pelo que ele significa enquanto processo econômico, político e social que precisa ser apreendido e, ainda mais, formulado teoricamente como um conceito do campo das ciências sociais que sintetiza a práxis histórica que exige ser confrontada.

Comecemos, então, com o questionado emprego do prefixo neo aposto aos termos de que tratamos aqui. Cabe advertir que não há como evitá-lo, a despeito dos riscos que traz. De fato, quando se parte do princípio de que o modo de produção capitalista opera um conjunto de determinações de ordem estrutural, o emprego do neo parecerá sempre indevido porque não há exatamente um novo, já que se poderia tratar, no máximo, de desdobramentos ou desenvolvimentos dessas determinações, ou seja, de um passado que se repõe permanentemente sob sua vigência. Contudo, é preciso admitir que pode haver, nesses desenvolvimentos, aspectos novos, embora não tão inteiramente novos, que modificam ou tornam mais complexa a análise dessa realidade. É nessa perspectiva que os prefixos indicativos de um novo são empregados aqui.

Depois, para se compreender o neoliberalismo é importante retomar o significado do substantivo liberalismo a que o prefixo se junta atualmente e, de início, já também advertimos, essa não é uma tarefa fácil. Segundo Matteucci (1998), a inexistência de um consenso quanto à definição de liberalismo deve-se a três ordens de explicação: 1 . a vinculação entre a história do liberalismo e a história da democracia, que traz por consequência a dificuldade em estabelecer o que há de liberal e de democrático nas democracias liberais; 2. a manifestação do liberalismo em tempos históricos distintos; e 3. a ausência de uma história de difusão predominante do liberalismo, visto que, em cada país, ele se defrontou com problemas políticos específicos. Além disso, lembra Matteucci, não há uma clara definição quanto aos referenciais históricos do termo, que podem indicar, conforme o caso, "um partido ou um movimento político, uma ideologia política ou uma metapolítica (ou uma ética), uma estrutura institucional específica ou a reflexão política por ela estimulada para promover uma ordem política melhor, justamente a ordem liberal" (MATTEUCI, 1998, p. 687). No entanto, pode-se admitir, genericamente, que o liberalismo é uma noção moderna que se fundamenta no princípio da liberdade, sobretudo da liberdade do indivíduo, no preceito da igualdade de direitos e na defesa do direito à propriedade privada.

Na sua origem, em particular com John Locke, o liberalismo é "filosófico e político", pois está "visceralmente ligado à filosofia dos direitos naturais, prega a tolerância política e religiosa, exige o direito de defesa contra o arbítrio e mostra-se coerente com a visão de mundo que advoga que os homens nascem livres, tanto quanto racionais" (PAULANI, 2005, p. 116-117). Na ideia de garantia e preservação dos princípios formais (e, portanto, abstratos) da igualdade e da liberdade, o liberalismo ainda pressupõe a existência de valores societários universais que, mesmo sendo irrealizáveis nos limites 
da sociedade capitalista, apresentam-se como princípios substantivos. Portanto, foi a partir do século XVIII, com Adam Smith, e, posteriormente, com John Stuart Mill, que o liberalismo incorporou seu inescapável viés econômico. Segundo Paulani, isso se deveu a três ordens de explicação: a associação já estabelecida por John Locke entre o liberalismo e a defesa do direito à propriedade privada, que, para ele, antecede a sociedade civil e se soma ao direito à vida e à liberdade; a associação entre o liberalismo e o princípio formal de igualdade (Rousseau); e o desenvolvimento da escola utilitarista na Inglaterra, com Bentham, seguido de John Stuart Mill. Como um desdobramento da escola liberal, o utilitarismo propõe que uma sociedade desprovida de relações hierárquicas estabelecidas alça garantir a coesão (e a ordem) com base no princípio da "felicidade geral", segundo o qual cada um age segundo o seu próprio interesse (PAULANI, 2005). Como bem sintetiza Marcuse (2006, p. 52):

O liberalismo é a teoria econômica e social do capitalismo industrial europeu naquele período em que o portador propriamente dito do capitalismo era o "capitalista individual", o empresário privado em seu sentido literal. Apesar de toda a diversidade estrutural do liberalismo e de seus defensores nos vários países e períodos, o seu fundamento uniforme se mantém: a liberdade do sujeito individual econômico em dispor da propriedade privada e a garantia jurídicoestatal dessa liberdade de disposição.

O triunfo do liberalismo na segunda metade do século XIX não foi uma tarefa fácil, como reitera Harold Laski $(1973$, p. 171) em seu estudo sobre o liberalismo europeu: teve de enfrentar muitas batalhas, em especial contra o conservadorismo e, o mais essencial, contra o emergente socialismo. De sua parte, os conservadores procuravam "fixar limites ao individualismo em nome de uma autoridade que, fosse a Igreja ou o Estado, impediria a queda da anarquia social que acreditavam ser inerente à ideia liberal" (LASKI, 1973, p. 171). Os socialistas, de outra parte, eram críticos do liberalismo entre outras razões por entenderem que seus princípios, longe de serem universais, expressavam os interesses de uma particularidade histórica cuja finalidade era tão somente o lucro. A despeito dessas oposições, o domínio do liberalismo se garantiu até a Primeira Guerra Mundial, exceção feita aos países em que prosperara o ideário socialista.

A grande crise de 1929 encerrou a fase "clássica" do capitalismo imperialista e, consequentemente, implicou um colapso dos valores e instituições liberais nos padrões até então compreendidos. Alguns setores mais lúcidos da burguesia passaram a perceber a necessidade de novas formas de intervenção do Estado na economia capitalista, tendo em vista "as condições gerais da produção e da acumulação" (NETTO; BRAZ, 2006, p. 193). Em países em que os princípios democráticos burgueses tinham sido estabelecidos de modo mais sólido, as formas de intervenção do Estado não violaram esses princípios. Em contrapartida, em países em que essas tradições eram mais frágeis, instalaram-se os regimes políticos fascistas.

Após a Segunda Guerra Mundial, emergiram variadas formas de Estados sociaisdemocratas na Europa e, em outros continentes, em países como os Estados Unidos e o Japão, cujo ponto em comum era, com base nos princípios gerais do keynesianismo: 
ampliar o poder do Estado, que deveria passar a concentrar-se "no pleno emprego, no crescimento econômico e no bem-estar de seus cidadãos" (HARVEY, 2008, p. 20). O período que se sucedeu foi de notável desenvolvimento desse ideário, os seus "anos dourados". Para Harvey (2008), esse período, denominado "liberalismo embutido", caracterizou-se pelas regulações que restringiam ou lideravam as estratégias econômica e industrial, tendo por consequência as taxas elevadas de crescimento econômico nos países de economia mais avançada nos anos de 1950 e de $1960^{5}$. O "liberalismo embutido" entrou em declínio a partir do final da década de 1960, com sinais de uma grave crise de acumulação, como o aumento do desemprego e a inflação acelerada. As alternativas ao Estado de Bem-Estar Social polarizaram-se: à esquerda, buscou-se aprofundar o controle e a regulação estatais da economia, preconizando a defesa da ação do Estado e do planejamento central; à direita, defendia-se a liberdade do mercado, desvinculando o capital das restrições da social-democracia. Em face de uma recessão, que gerava apreensão no que diz respeito ao aperto do poder econômico e político das elites e ao risco de uma solução socialista, a resposta que se tornou hegemônica foi o processo de neoliberalização, em especial a partir dos anos de 1990, com a articulação de um conjunto de medidas que passaram a ser designadas como o "Consenso de Washington"6.

O ideário neoliberal teria como ponto de partida a reunião de um grupo pequeno e ilustre de economistas, historiadores e filósofos em torno do filósofo político Friedrich von Hayek, com a finalidade de criar a Mont Pelerin Society, em 1947. Hayek visava tanto uma investida contra o marxismo e o socialismo, como uma investida contra o planejamento estatal e o intervencionismo keynesiano do Estado de Bem-Estar Social. Ele reconhecia que seria necessário travar uma longa e sistemática batalha de ideias para que esses objetivos fossem alcançados, o que efetivamente ocorreu com forte apoio institucional e financeiro ao longo das décadas seguintes.

Segundo Harvey (2008, p. 11), alguns fatos que marcaram os fins dos anos de 1970 sinalizaram a ruptura da história social e econômica mundial que estava por vir: em 1978, Deng Xiaoping iniciava um processo que iria transformar a China na potência que é hoje; em 1979, Paul Volcker assumia o controle do Banco Central dos Estados Unidos (FED) e mudava a política monetária, combatendo a inflação sem se preocupar com o aumento do desemprego; em 1979, Margareth Thatcher era eleita Primeira-Ministra da GrãBretanha, com a missão de diminuir a ação dos sindicatos e combater a inflação; em 1980, Ronald Reagan, eleito presidente dos Estados Unidos, apoiou as decisões do FED e desenvolveu "políticas destinadas a diminuir o poder do trabalho, desregular a indústria, a agricultura e os setores extrativistas, assim como liberar os poderes das finanças tanto internamente como no cenário mundial" (HARVEY, 2008, p. 11).

Esses acontecimentos dos países centrais foram precedidos por um experimento realizado em uma brutal ditadura latino-americana (HARVEY, 2008, p. 19). Na década de 1970, após o golpe de Estado no Chile patrocinado pelas elites chilenas e apoiado por corporações estadunidenses, pela CIA e pelo Secretário de Estado Henry Kissinger, economistas vinculados a Milton Friedman (Universidade de Chicago), denominados "Chicago Boys", foram convidados a colaborar com o ditador Pinochet na redefinição da política econômica do país. Entre outras ações, esses economistas reverteram

as nacionalizações e privatizaram os ativos públicos, liberaram os recursos naturais [...] à exploração privada e não-regulada (em muitos casos reprimindo brutalmente as reivindicações das populações 
indígenas), privatizaram a seguridade social e facilitaram os investimentos estrangeiros diretos e o comércio mais livre. $O$ direito de companhias estrangeiras repatriarem lucros de suas operações chilenas foi garantido. $O$ crescimento gerado pelas exportações passou a prevalecer sobre a substituição de exportações. (HARVEY, 2008, p. 18).

De modo que o processo de neoliberalização seria operado de diferentes maneiras, em diversos tempos e em muitos lugares do mundo a partir dos anos de 1980, compreendendo os principais países da Europa, da América do Norte, da América Latina, da Ásia. Em cada um desses lugares desenrolaram-se enredos diferentes, que assumiram características muito distintas, ainda que orientados por preceitos gerais neoliberais. Isso significa que - a concordar com Harvey - foi levado a cabo um conjunto de mudanças que afetou a economia, o Estado, a sociedade e a subjetividade dos indivíduos e permitiu restaurar, ou construir, no caso da China e da Rússia, um poder de classe incontestável.

O neoliberalismo foi, portanto, desde seu início, um projeto de recomposição de um poder de classe (DUMÉNIL; LÉVY, 2014), ou seja, um "projeto político de restabelecimento das condições de acumulação do capital e de restauração do poder das elites econômicas" (HARVEY, 2008, p. 27). Nesse processo, ganhou protagonismo uma nova administração de alto escalão comprometida com as classes capitalistas e que, paralelamente, promoveu a desregulamentação de todos os setores, favorecendo a hegemonia financeira, ao mesmo tempo em que assegurou medidas protetoras para os negócios e os investimentos. O Estado neoliberal exerceu forte pressão sobre os trabalhadores assalariados, restringiu seu poder de compra, promoveu a precarização das condições de trabalho, reprimiu os sindicatos e muitas outras medidas que retiraram direitos e benefícios disponíveis e aprofundaram as formas de exploração da força de trabalho.

É assim que, por todas essas condições, a conceituação do neoliberalismo precisa que se levem em conta diferentes contextos e diferentes processos envolvidos em distintos países. Em linhas gerais, ele pode ser entendido como uma doutrina e uma política econômica fundadas na ideia de que o mercado deve prevalecer sobre todos os setores da vida humana, dos mais universais aos mais particulares. Envolve ideias e práticas que aprofundam a desigualdade econômica e levam à perda de valores e ideais políticos e sociais: o neoliberalismo "manteve e mantém uma campanha inexorável contra tudo o que possa parecer 'social', de modo a priorizar tudo o que possa ser ou parecer 'econômico'" (IANNI, 2004, p. 332).

Entretanto, resta perguntar: em que se distinguiria, afinal, esse "novo liberalismo" do liberalismo original? Segundo Paulani (2005, p.124), pelo menos duas diferenças podem ser identificadas: primeira, o neoliberalismo teria deixado de se caracterizar como uma doutrina de cunho político, filosófico e/ou moral para se limitar a uma doutrina econômica ou a "uma receita de política econômica"; segunda, que ele não daria margem a qualquer forma de dissenso, passando a exigir, com o amparo da pretensa superioridade do mercado, a crença nas virtudes do capitalismo e da livre concorrência: 
Confirmando sua natureza de puro receituário econômico destinado a recolocar o mercado no lugar que de direito lhe pertence, essa característica onipresente do neoliberalismo tem levado, no limite, a transformar o processo politicamente moderno de nossas sociedades em meros rituais vazios, sem nenhuma importância, processos que em nada modificam o curso inexorável da marcha econômica. (PAULANI, 2005, p. 126).

Fazendo um balanço de seus resultados, Harvey (2008) avalia que, de modo geral, a neoliberalização tem fracassado em seu propósito de estimular a acumulação do capital. Isso não impediu, entretanto, que ela continuasse a ser apontada por muitos como bem-sucedida e como a "única alternativa". Essa hegemonia do ideário econômico neoliberal poderia ser explicada, para além da propaganda dos think tanks neoliberais, por seus desenvolvimentos desiguais em diferentes países, cuja dinâmica volátil permite que o sucesso de um contribua para encobrir os insucessos de outros, e também pelo fato de que tem sido exitoso o propósito da restauração do poder de classe (HARVEY, 2008).

Harvey destaca, também, algumas mudanças importantes ocorridas sob o neoliberalismo: a neoliberalização significou a " 'financeirização' de tudo" (HARVEY, 2008, p. 41); incorporou o espetacular avanço das tecnologias da informação em um mundo "globalizado"; e, o que considera o seu feito mais substantivo, redistribuiu, em vez de criar, riqueza e renda (HARVEY, 2008, p. 171). Para compreender essa redistribuição de renda, Harvey recorre ao conceito de "acumulação por espoliação", para designar vários processos em curso, como a privatização de ativos públicos, a financeirização da economia, a administração e manipulação de crises e a redistribuição operada mediante a ação do Estado 8 .

A crise financeira de 2008 nos Estados Unidos representou, para alguns analistas, uma crise do próprio neoliberalismo, que viam ali os sinais de seu enfraquecimento. Mas os anos que se seguiram parecem não demonstrar isso: o neoliberalismo tem se fortalecido e se renovado em muitos aspectos. Os sociólogos franceses Dardot e Laval (2016, p. 17), com base em uma interpretação foucaultiana, atribuem a vitalidade do neoliberalismo ao fato de que, antes de ser uma ideologia ou uma política econômica, ele seria fundamentalmente uma racionalidade peculiar, cuja principal característica é "a generalização da concorrência como norma de conduta e da empresa como modelo de subjetivação". Consideram, inclusive, que estaria em desenvolvimento uma nova etapa do neoliberalismo, cujo marco é o governo de Donald Trump nos Estados Unidos. Esse novo neoliberalismo representaria uma grave ameaça à democracia e teria como característica a capacidade de se apropriar em seu favor das consequências das crises que ele próprio produz: "[...] é como se o neoliberalismo aproveitasse a crise da democracia liberal-social que provocou e não cessa de agravar para impor melhor a lógica do capital sobre a sociedade" (DARDOT; LAVAL, 2019, não paginado).

$\mathrm{Na}$ América do Sul em particular, o neoliberalismo tem sido retomado a partir da ascensão da direita em países como Argentina e Brasil, encerrando um período de governos neodesenvolvimentistas de centro-esquerda na região. Buscando compreender essa nova etapa neoliberal, García Delgado e Grandin (2016a, 2017) designam como "neoliberalismo tardio" a atual conjuntura econômica, social e geopolítica desses países, que apresenta "cambios estructurales tanto en los modelos de acumulación, los patrones de distribución de riqueza y de poder, como en las subjetividades promovidas por los 
medios masivos de comunicación y por las redes sociales" (GARCÍA DELGADO; GRANDIN, 2017, p. 17). Essa etapa se caracteriza por:

[...] una feroz disputa por la reestructuración de la distribución de la riqueza a favor de los sectores concentrados de la economía; por el inicio de un nuevo proceso de endeudamiento externo; la apertura de la economía; la desindustrialización; y el intento deliberado de bajar salarios y niveles de consumo de los sectores mayoritarios. (GARCÍA DELGADO; GRANDIN, 2017, p. 17).

O neoliberalismo tardio tem como antecedentes, na América do Sul, dois movimentos da região: o primeiro, que emergiu com a crise do Estado de Bem-Estar Social em meados da década de 1970, e o segundo, no final da década de 1980 e na década seguinte, afinado com o Consenso de Washington. No início deste século, com a ascensão dos governos progressistas na região, seguiu-se uma etapa "pós-neoliberal" de heterodoxia econômica, com um paradigma "produtivo-inclusivo", que visava à revalorização do Estado, dos direitos sociais e da política. Como assinalam García Delgado e Grandin (2017, p. 20), os desdobramentos da crise de 2008 no cenário do capital internacional impactaram as economias desses governos, "abrindo a porta para o neoliberalismo tardio".

No Brasil, o golpe de Estado de 2016 adotou os preceitos e as medidas do credo neoliberal em uma conjuntura mundial diversa de sua fase original dos anos de 1990 . Foi precedido por um documento programático chamado Uma ponte para o futuro, elaborado pela Fundação Ulisses Guimarães (PMDB, 2015), cuja finalidade era a retomada da agenda neoliberal, tendo como principal alvo a Constituição de 1988. A aprovação, ainda em 2016, da Emenda Constitucional do Teto dos Gastos Públicos (PEC 241/P 55 EC 95), que limita as despesas do governo brasileiro durante os próximos vinte anos, demarcou o que estaria por vir nos governos de direita de Temer e, exponencialmente aprofundado, de Bolsonaro a partir de 2019.

García Delgado e Gradin (2017) identificam nessa etapa atual do neoliberalismo na América do Sul, na qual se insere o Brasil, alguns aspectos que consideram indicativos de uma nova configuração de poder: 1 . a especialização produtiva, o endividamento externo e o "volver al mundo", nos termos de uma inserção subordinada aos países centrais, em especial os Estados Unidos; 2. as restrições impostas ao regime democrático e a judicialização da política; 3 . a construção de consensos e "a batalha cultural"; 4. a fragmentação social e política; 5 . a composição dos governos com uma nova elite empresarial (os CEOs) e uma nova reforma estrutural do Estado.

Esses aspectos podem ser identificados no neoliberalismo à brasileira em sua etapa tardia, que, além de açambarcar o receituário neoliberal "clássico" em doses maciças e intensivas - privatizações, desregulamentação da economia, flexibilização das leis trabalhistas, reforma da previdência, reforma tributária, redução de gastos públicos, abertura comercial, abertura para investimentos estrangeiros, entre mais -, incorpora novas prescrições muito semelhantes àquelas descritas por García Delgado e Gradin. Podem ser destacadas algumas intervenções sobre a economia, como a desarticulação da indústria brasileira, o retorno à prevalência da exportação de bens primários e a 
privatização do sistema energético nacional. Esse conjunto de medidas, as clássicas e as novas, aprofunda o processo de recomposição da hegemonia da fração da burguesia brasileira que representa os interesses do neoliberalismo em sua formulação mais ortodoxa, integrada ao capital internacional, em especial o estadunidense.

Mesmo dispondo de todo um arsenal para assegurar a efetivação de sua contrarreforma, contando inclusive com a maciça adesão de toda a mídia dominante, as elites econômicas e suas bases de apoio tradicionais encontram dificuldade para impor suas medidas neoliberais. Pelo que já foi dito: pela impossibilidade de esconder seus insucessos e de lidar com o descontentamento por ele gerado, tarefa muito mais dificultada após os extraordinários protestos no Chile, em 2019. Como já antevia Harvey (2008, não paginado) em 2005, "a consolidação do neoconservadorismo autoritário surge então como possível reação". Isso implica novos arranjos na composição de poder e o aprofundamento de expedientes que, por sua natureza profundamente autoritária, põem em risco a democracia burguesa. Se o interesse do mercado deve prevalecer sobre os interesses sociais, o Estado tudo fará para que prevaleça o interesse do mercado, o que requer ações violentas, em grande intensidade e amplitude, exercidas sempre que necessárias. Enfim, o neoliberalismo, em todos os seus momentos e, particularmente, no presente, não combina com a democracia.

Com efeito, a extrema direita tem crescido em todo o mundo, podendo ser identificadas algumas evidentes distinções e semelhanças entre esses movimentos, como observa Löwy (2019b, p. 1-2):

Em cada país esta extrema direita tem características próprias: em muitos países (Europa, Estados Unidos, Índia, Birmânia) o "inimigo" isto é, o bode expiatório - são os muçulmanos e os imigrantes; em certos países muçulmanos são minorias religiosas (cristãos, judeus, yezhidis). Em alguns casos predominam o nacionalismo xenofóbico e o racismo, em outros o fundamentalismo religioso, ou então o ódio à esquerda, ao feminismo, aos homossexuais.

Apesar dessa diversidade há alguns traços comuns à maioria, senão a todos: 0 autoritarismo, o nacionalismo integral - "Deutschand über alles" e suas variantes locais: "America First", "O Brasil acima de tudo", etc. - a intolerância religiosa ou étnica (racista) contra o "Outro", a violência policial/militar como única resposta aos problemas sociais e à criminalidade.

Em face do avanço da extrema-direita no Brasil, intensificado desde os movimentos que antecederam o golpe de Estado de 2016, Michael Löwy (2019a) identifica alguns pontos em comum entre as atuações de Trump, Bolsonaro e outros extremistas de direita europeus: o autoritarismo, que se manifesta pela "adesão a um homem forte, um líder capaz de "restaurar a ordem"; a ideologia repressiva, "o culto da violência policial, o apelo ao restabelecimento da pena de morte e a distribuição de armas à população para a sua "defesa contra os criminosos"; e a intolerância contra minorias sexuais (LÖWY, 2019a). Elas se distinguiriam no que concerne à importância dada, no Brasil, à "luta contra a corrupção" e ao ódio à esquerda ou à centro-esquerda, o que as aproximaria "do fascismo clássico, com seu culto de violência e ódio visceral da esquerda e do movimento trabalhista" (LÖWY, 2019a, não paginado), questões que não ocupam um lugar central nos Estados Unidos e na Europa (lembrando que esta última tem no 
racismo a sua bandeira principal). $E$, ainda, se distinguiriam pela adoção de um programa ultraneoliberal, justo no momento em que "a extrema direita europeia denuncia a globalização neoliberal, em nome do protecionismo, do nacionalismo econômico, contra as 'finanças internacionais'" (LÖWY, 2019a, não paginado).

Boito Jr. caracteriza o governo Bolsonaro como neofascista, com características distintas do fascismo original, entendendo que ambos são modalidades de um mesmo gênero, ou seja, do gênero fascismo, que pode ser apresentado como um "movimento reacionário de massas, enraizado em classes intermediárias das forças sociais capitalistas e movido por um discurso superficialmente crítico da economia e do Estado burguês" (BOITO JR., 2019b, p. 3). Isso seria possível mesmo considerando que, em lugar de defender um nacionalismo, o governo adote uma política externa de subordinação aos Estados Unidos, em função do posicionamento assumido pelo bloco do poder dominante que, como já discutido aqui, defende os interesses do capital internacional. Boito Jr. entende também que a caracterização de uma ditadura fascista supõe a distinção entre a forma de Estado, o movimento e a ideologia. No caso brasileiro, haveria uma ideologia fascista e um movimento neofascista que ocupam uma posição dominante no governo. Não haveria, contudo, pelo menos até o presente, um regime político fascista: "[...] o regime vigente no Brasil é uma democracia burguesa deteriorada e em crise" (BOITO JR., 2019 b, p. 2). Essa discussão é importante porque, concordando com Boito Jr., modifica a compreensão da forma do Estado e seus desdobramentos na prática política. Considerar que a luta ideológica empreendida pelos fascistas adota "um discurso superficialmente crítico e profundamente reacionário", por exemplo, permite compreender o grande impacto popular desse discurso e como ele torna mais difícil o seu combate por parte das esquerdas que, afinal, são o seu maior alvo (BOITO JR., 2019a, p. 6).

Está claro que o neoliberalismo, em sua versão autoritária e neoconservadora, vem incidindo sobre a educação brasileira de modo avassalador desde 2016, agravado depois de 2019 ao ser encabeçado por um governo com características neofascistas. Muitos estudos da área já se dedicam a identificar onde e como tem se dado a desregulamentação de amplos setores do campo, demarcando seus desdobramentos e implicações que passam a ser objeto de análise dos educadores. Neste artigo, a intenção é indicar alguns pontos que merecem nossa atenção.

O fundamental a ser compreendido quando se trata do neoliberalismo é que ele tem acirrado o processo de promoção da mais brutal desigualdade de renda e de condições sociais visto na história. Essa realidade impacta a educação sob todos os pontos de vista e tem como resultado mais imediato os processos de mercantilização e de privatização, que incidem direta e indiretamente sobre a educação escolar em todos os níveis de ensino. Isso significa que o princípio de que caberia ao Estado a responsabilidade pela educação pública vai se desfazendo ou, no mínimo, se deslocando para o atendimento exclusivo das demandas dos muito pobres. Tudo isso implica novas formas de discriminação e aprofundamento de desigualdades sociais, que põem em causa a luta pela defesa da educação, seja ela entendida como educação escolar ou como educação em sua acepção mais ampla, como formação humana.

Mas o processo de neoliberalização tardio com características fascistas tem demonstrado um apetite feroz pelo controle ideológico da escola, adotando práticas 
autoritárias de toda a sorte não apenas em prejuízo dos processos democráticos e participativos de educação, mas de preceitos básicos, como o respeito pelo espaço da escola e da sala de aula, orientados pelos princípios da autonomia e da livre expressão. Em decorrência, ampliam-se e aprofundam-se as formas de destituição da soberania e da autoridade do professor e da professora. São desacreditadas todas as formas que não aquelas movidas pelos interesses da acumulação ou do conservadorismo extremado. $O$ professor, já submetido a todo tipo de exploração de sua força de trabalho, sofre as consequências físicas e psicológicas desse processo, que busca desautorizar e até mesmo criminalizar suas ações. Como resultado, vai sendo "naturalizada" a violência direcionada à escola e ao professor. A escola, como as demais instituições, tende a reproduzir internamente os conflitos sociais. Contudo, se, por princípio, ela deveria ser um espaço de proteção e de projeção de um futuro para nossas crianças e jovens, a conversão da escola em alvo de violência física e simbólica nos níveis em que vem ocorrendo, particularmente no que se refere à escola pública, é um grave indicador de discriminação e mesmo abandono de grande parte da população.

Do ponto de vista ideológico, a propagação e a naturalização de crenças terraplanistas, criacionistas e outros obscurantismos de toda ordem passam a desacreditar as diferentes manifestações do pensamento racional. Até mesmo a crítica à ciência, em geral reservada às ciências sociais, se estende agora para qualquer campo do conhecimento que contrarie qualquer preceito real ou imaginário dos interesses dominantes. Tais manifestações só na aparência poderiam ser consideradas irracionais, uma vez que são parte de uma lógica que compõe as estratégias de dominação sob o neoliberalismo. Se a terra é plana, em que bases se sustentaria a educação?

Esses pontos - que apenas indicam desdobramentos do processo de neoliberalização sobre a educação - são também indicadores da urgência e da natureza da luta a ser travada. A voracidade com que se produzem os ataques a esse campo na atualidade, antes que ocultar, é expressão da sua importância estratégica na guerra em curso. Por mais difícil que seja o confronto com essa realidade, este certamente não é mais difícil do que a própria realidade. Enfrentar esse desafio foi o propósito desta discussão.

\section{NEOLIBERALISM AS A NEOCONSERVATIVE OFFENSIVE TO EDUCATION IN BRAZIL}

ABSTRACT: The purpose of this article is to introduce a debate on neoliberalism in its conceptual and historical aspects, in view of the challenges posed by this process in its new stage in Brazil and some of its particularities. For that, the starting point is a discussion about liberalism, with the purpose of locating the bases that will be preserved or recreated under contemporary neoliberalism, always with the concern to situate, historically and conceptually, the processes that are proper to the way of capitalist production. Then, we intend to apprehend the constitutive aspects of this neoliberalism and place them in the perspective of its contemporary developments and some issues related to education as a social policy, a dimension of culture or a school practice. 
KEYWORDS: Neoliberalism. Neoliberalism and education. Neoconservatism.

\section{NEOLIBERALISMO COMO UNA OFENSIVA NEOCONSERVADORA PARA LA EDUCACIÓN EN BRASIL}

RESUMEN: El propósito de este artículo es introducir un debate sobre el neoliberalismo en sus aspectos conceptuales e históricos, en vista de los desafíos que plantea este proceso en su nueva etapa en Brasil y algunas de sus particularidades. Para eso, el punto de partida es una discusión sobre el liberalismo, con el propósito de ubicar las bases que serán preservadas o recreadas bajo el neoliberalismo contemporáneo, siempre con la preocupación de situar, histórica y conceptualmente, los procesos que son apropiados para el camino de producción capitalista. Luego, pretendemos comprender los aspectos constitutivos de este neoliberalismo y colocarlos en la perspectiva de sus desarrollos contemporáneos y algunos temas relacionados con la educación como política social, una dimensión de la cultura o una práctica escolar.

PALABRAS CLAVE: Neoliberalismo. Neoliberalismo y educación. Neoconservadurismo.

\section{NOTAS}

1. A financeirização do capital corresponde à fase atual do estágio do desenvolvimento do capitalismo conhecido como imperialismo, cuja organização se caracteriza pela busca do aumento da taxa de lucro dos monopólios e da reversão de seus riscos. A financeirização é a etapa do imperialismo marcada pelo "fabuloso crescimento (em função da superacumulação e da queda das taxas de lucros) dessa massa de capital dinheiro que não é investida produtivamente, mas que succiona seus ganhos (juros) de mais valia-global" (NETTO; BRAZ, 2006, p. 231-232, grifo dos autores).

2. Entre outras publicações da área de educação, podem ser mencionadas as coletâneas de Gentili e Silva (1994), Warde (1998), os textos de Frigotto (1994), Silva (1994), Apple (2003), Donoso Torres (1999), Gentili $(1995,1998)$.

3. Pode-se identificar nessa passagem a influência de Michel Foucault, uma perspectiva de análise do neoliberalismo hoje aprofundada e muito disseminada, como em Dardot e Laval (2016), Brown (2016) e muitos outros. Nas obras citadas na nota anterior predominava o enfoque marxista, secundado pelas análises pós-estruturalistas. Essa correlação parece ter-se invertido com o passar dos anos em boa parte da literatura sobre essa temática, uma tendência não ratificada por este artigo.

4. As aproximações e distanciamentos dos governos do PT com relação ao processo de neoliberalização iniciado no governo anterior não serão tratadas neste artigo. Na ausência dessa discussão, é oportuno trazer a hipótese proposta por Crespo e Ghibaudi (2019, p. 30) referindo-se aos países da América Latina, em especial da América do Sul, no mesmo período: "los gobiernos progresistas son una resistencia político-social - socialmente construida - dentro de un proceso más amplio e duradero de neoliberalización mundial, y que no consiguió - por opción, omisión o impotencia - revertir sus condiciones estructurales y sistémicas".

5. Convém lembrar que, para boa parte do chamado Terceiro Mundo, nesse período, em especial a África, o liberalismo embutido permaneceu como "um sonho distante". (HARVEY, 2008, p. 21). 
MIRANDA, M. G. de

6. "A expressão Washington Consensus foi usada, pela primeira vez [1990], por John Williamson, pesquisador do Institute for International Economics, um dos mais célebres think tanks norteamericanos. O programa de ajuste e estabilização proposto no marco desse 'consenso' inclui dez tipos específicos de reforma que, como assinala Williamson, foram quase sempre implementados com intensidade pelos governos latino-americanos a partir da década de oitenta" (GENTILI, 1998, p. 14).

7. Para os sociólogos franceses Pierre Dardot e Christian Laval (2016), o momento fundador do neoliberalismo foi anterior à Mont Pelerin Society e teria ocorrido em Paris no ano de 1938 no Colóquio Walter Lippman, vinculado ao Instituto Internacional de Cooperação Intelectual (antecessor da Unesco). Dardot e Laval consideram que a diferença no estabelecimento dos marcos tem consequências importantes para a análise do neoliberalismo.

8. O conceito de "acumulação por espoliação" daria continuidade ao de "acumulação primitiva" empregado por Karl Marx ao tratar dos processos originais do capitalismo.

\section{REFERÊNCIAS}

APPLE, Michael. Educando à direita: mercados, padrões, Deus e desigualdade. São Paulo: Cortez; Instituto Paulo Freire, 2003.

BOITO Jr., Armando. Os atores e o enredo da crise política. In: JINKINS, Ivana; DORIA, Kin; CLETO, Murilo. Por que gritamos golpe? Para entender o impeachment e a crise política no Brasil. São Paulo: Boitempo, 2016. p. 23-29.

BOITO Jr., Armando. Reforma e crise política no Brasil: os conflitos de classe nos governos do PT. Campinas, SP: Ed. Unicamp; São Paulo: Ed. Unesp, 2018.

BOITO JR., Armando. As dificuldades da luta popular diante do fascismo. Brasil de Fato. 12 abr. 2019a. Disponível em: <https://www.brasildefato.com.br/2019/04/12/artigo-oras-dificuldades-da-luta-popular-diante-do-fascismo-por-armando-boito-jr/>. Acesso em: 16 maio 2019.

BOITO Jr., Armando. A terra é redonda e o governo Bolsonaro é fascista. A terra é redonda. 2019b. Disponível em: <https://aterraeredonda.com.br/a-terra-e-redonda-e-ogoverno-bolsonaro-e-fascista/>. Acesso em: 17 out. 2019.

BROWN, Wendy. American nightmare: neoliberalism, neoconservantism, and democratization. Political Theory, v. 34, n. 6, p. 690-714, 2006.

CRESPO, Eduardo; GHIBAUDI, Javier. El proceso neoliberal de larga duración y los gobiernos progresistas en América Latina. In: DOCUMENTO DE TRABALHO n. 5. El neoliberalismo tardio: teoría y práxis. Buenos Aires: Flacso, 2017.

DARDOT, Pierre; LAVAL, Christian. A nova razão do mundo: ensaio sobre a sociedade neoliberal. São Paulo: Boitempo, 2016. 
DARDOT, Pierre; LAVAL, Christian. A nova fase do "neoliberalismo". Outras mídias. 29 jul. 2019. Disponível em: $<$ https://outraspalavras.net/outrasmidias/dardot-e-laval-a-novafase-do-neoliberalismo/>. Acesso em: 16 maio 2019.

DONOSO TORRES, Roberto. Mito y educación: el impacto de la globalización em la educación en Latinoamérica. Buenos Aires: Espacio Editorial, 1999.

DUMÉNIL, Gérard; LÉVY Dominique. A crise do neoliberalismo. São Paulo: Boitempo, 2014.

FRIGOTTO, Gaudêncio. Educação e formação humana: ajuste neoconservador e alternativa democrática. In: GENTILI, Pablo A. A.; SILVA, Tomaz T. da. Neoliberalismo, qualidade total e educação. Petrópolis: Vozes, 1994. p. 31-92.

GARCÍA DELGADO, Daniel; GRADIN, Agustina. Neoliberalismo tardio: entre la hegemonia y la inviabilidade. El cambio de ciclo en la Argentina. In: DOCUMENTO DE TRABALHO n. 5. El neoliberalismo tardio: teoría y práxis. Buenos Aires: Flacso, 2017.

GENTILI, Pablo A. A. Adeus à escola pública: a desordem neoliberal, a violência do mercado e o destino da educação das maiorias. In: GENTILI, Pablo A. A. (Org.). Pedagogia da exclusão: crítica ao neoliberalismo na educação. Petrópolis: Vozes, 1995.

GENTILI, Pablo A. A. A falsificação do consenso: simulacro e imposição na reforma educacional sob o neoliberalismo. Petrópolis: Vozes, 1998.

GENTILI, Pablo A. A.; SILVA, Tomaz T. da. Neoliberalismo, qualidade total e educação. Petrópolis: Vozes, 1994. p. 9-29.

HARVEY, David. O neoliberalismo: história e implicações. São Paulo: Loyola, 2008.

IANNI, Octavio. Capitalismo, violência e terrorismo. Rio de Janeiro: Civilização Brasileira, 2004.

LASKI, Harold J. O liberalismo europeu. São Paulo: Mestre Jou, 1973.

LÖWY, Michel. A extrema-direita: um fenômeno global. Esquerda on line. 2019a. Disponível em: $<$ https://esquerdaonline.com.br/2019/01/15/a-extrema-direita-umfenomeno-global/>. Acesso em: 15 jan. 2019.

LÖWY, Michel. Neofascismo: um fenômeno planetário - o caso Bolsonaro. A terra é redonda. 2019b. Disponível em: <https://aterraeredonda.com.br/neofascismo-umfenomeno-planetario-o-caso-bolsonaro>. Acesso em: 29 out. 2019. 
MIRANDA, M. G. de

MARCUSE, Herbert. O combate ao liberalismo na concepção totalitária de Estado. Cultura e Sociedade, São Paulo: Paz e Terra, v. 1, n. 2, 2006.

MATTEUCCI, Nicola. Liberalismo. In: BOBIO, Norberto; MATTEUCCI, Nicola; PASQUINO, Gianfranco (Ed.). Dicionário de política. 1. ed. Brasília, DF: Ed. UnB, 1998. p. 686-705. Disponível em: <https://edisciplinas.usp.br/pluginfile.php/4197102/mod_resource/content/1/BOBBIO. \%20Dicion\%C3\%A1 rio\%20de\%20pol\%C3\%ADtica.pdf>. Acesso em: 29 out. 2019.

NETTO, José Paulo; BRAZ, Marcelo. Economia política: uma introdução crítica. São Paulo: Cortez, 2006.

PMDB - Partido do Movimento Democrático Brasileiro. Uma ponte para o futuro. Brasília: Fundação Ulysses Guimarães, 2015. Disponível em: https://www.fundacaoulysses.org.br/wp-content/uploads/2016/11/UMA-PONTE-PARAO-FUTURO.pdf. Acesso em: 12 set. 2016.

PAULANI, Leda. Modernidade e discurso econômico. São Paulo: Boitempo, 2005.

SILVA, Tomaz Tadeu da. A "nova" direita e as transformações na pedagogia da política e na política da pedagogia. In: GENTILI, Pablo A. A.; SILVA, Tomaz Tadeu da. Neoliberalismo, qualidade total e educação. Petrópolis: Vozes, 1994. p. 9-29.

WARDE, Mirian (Org.). Il Seminário Internacional Novas Políticas Educacionais: críticas e perspectivas. São Paulo: PUC-SP, 1998.

Marília Gouvea de Miranda: Doutora em História e Filosofia da Educação pela Pontifícia Universidade Católica de São Paulo - PUC/SP (1991), Mestre em Educação pela Universidade Federal de São Carlos (1983), graduada em Psicologia pela Universidade Federal de Minas Gerais (1975). Professora Titular aposentada na Faculdade de Educação, da Universidade Federal de Goiás, e Voluntária no Programa de Pós-Graduação em Educação, nos cursos de mestrado e doutorado. Tem investigado a questão do aprofundamento da desigualdade social, em especial na sua vinculação com o neoliberalismo, analisando, dentre seus desdobramentos, o avanço do conservadorismo e do autoritarismo $e$ seus efeitos na educação.

Orcid: https://orcid.org/0000-0003-1947-2545

E-mail:mgmiranda8888@gmail.com

Este periódico utiliza a licença Creative Commons Attribution 3. 0, para periódicos de acesso aberto (Open Archives Iniciative - OAD). 